\title{
Focus as a Tool for the Success of Entrepreneurial Ventures; A Case of Selected Small and Medium Enterprises in Migori County
}

\author{
Joseph Musyoki ${ }^{1}$ and Jacqueline Korir ${ }^{2}$ \\ ${ }^{1}$ (School of Tourism, Hospitality and events management, Moi University, P.O Box 3900 Eldoret, Kenya.) \\ ${ }^{2}$ (School of Tourism, Hospitality and events management, Moi University, P.O Box 3900 Eldoret, Kenya.)
}

\begin{abstract}
Entrepreneurship is very key to initiation and implementation of any new business idea or venture, to bring the undertaking to its operational existence. To achieve this, an individual needs to use personal intuition and focus on the opportunities, challenges and the weaknesses as well as the strengths of the venture. The purpose of the study was to explore focus in entrepreneurship as a tool for success of business ventures. The study was significant in highlighting how entrepreneurs use focus as a tool for scanning to thrive in a competitive business environment. The study was conducted in Rongo town, in Migori County. Document analysis was used to form the basis of analysis for this research. In addition, interviews were conducted and observations made on the character of the research participants. The findings revealed focus is an important driver for entrepreneurial success. It was also found out that focus is a personal attribute that varies from one entrepreneur to another. The researcher recommends that both existing and potential entrepreneurs should use focus strategy to scan the business environment in order to mitigate the forces that influence the success of their ventures.
\end{abstract}

Keywords: Focus, Entrepreneur, Entrepreneurship

\section{Introduction}

Entrepreneurship has become very significant to the development of economies. Small and medium businesses are strongly connected to the concept of entrepreneurship, which is the key driving force of the developing economies in the world market. Entrepreneurship benefits the world economies where entrepreneurs can only function flexibly, develop personal and individualized ideas, and convert them in to viable business ventures. The Entrepreneurs overcome regulatory barriers by moving to more innovation-friendly economies or by embarking to non-wealth-creating activities from productive activities. In order to have productive entrepreneurs, developing countries need to streamline business regulatory rules, and prepare for the negative outcomes of layoffs in business organizations that fail because of the emerging competition. To achieve that objective, focus in to activities of entrepreneurial ventures is very instrumental. According to oxford advanced learners dictionary, the word focus means the center of interest or activity. It further defines focus as directing attention, feelings, comments or efforts to a particular problem or situation.

Entrepreneurs use of the focus strategies that recognize that all markets as unique from one another. In any given market, various customer segments exist, each with different characteristics, needs and wants. The primary impression here is that the entrepreneur must focus on one more segment(s); distinguish the customers who have special interests needs and wants; then serve them with an appropriate product or service designed to stand out in satisfying of exceeding the satisfaction of those interests, needs and wants. Focus in entrepreneurship builds on the uniqueness among the existing segments of the market. Entrepreneurs focus on serving niches in markets that other market players are underestimating or overlooking rather than serving the entire market.

The focus insights of entrepreneurs can be synthesized by identifying entrepreneurial functions that are shared across all disciplines. For effectiveness in focusing, entrepreneurs need to exercise good judgment in decision- making (Casson, 1982). Their judgment will enable them to come to a sound, defensible decision in the absence of complete information as the foundation of their focus potential towards the success of their business.

A focus strategy helps many entrepreneurs who have small and medium business firms, which may lack adequate resources to reach markets from either, regional national or global scale. Their purpose is to serve their narrow markets more effectively and efficiently than the competitors who operate the broad market as the center of their target. The basic foundation for entrepreneurial application of focus approach involves beginning the business by serving a small geographic area, with a specific group of consumers who may have similar wants, needs or interests, for example, consumers of left-handed products. 
Many times, divergent and imaginative entrepreneurs tend to notice opportunities or problems and focus on provision of products and services to serve those markets. For entrepreneurs to develop divergent thinking, they do not need to constrain themselves with predefined solutions to the problems at their attention. While inquisitiveness and thoughtfulness are unquestionably indispensable for noticing what product is missing and what might be an entrepreneurial opportunity, the key to success of any venture is focus where the entrepreneur must do nothing else that to focus, focus, and focus. The following guidelines help the entrepreneurs to focus on potential business opportunities by analyzing them: Learning to define issues as more than is immediately visible; Going beyond the symptoms to the core issue; Isolating what you are looking for and focus on what is the underlying issue or problem; Engaging the problem and search for information. Good entrepreneurs create an expertise in data gathering; Finding the pertinent facts and not ignoring the information that is contradictory to entrepreneurs' expectations and analyzing data and using well-established logical models.

Entrepreneurs need to comprehend the issues around the potential opportunity, meaning, and entrepreneurs should knowing something is right before it can be consciously explained. Therefore, they should blend facts with their own intuition. While it is important to make use of prior training and education, it is equally important not to be constrained by it. Entrepreneurs need to accept that entrepreneurial process is not going to be easy, engage self with the problem and feel passionate about solving it while at the same time expecting uncertainty.

To strengthen their focus, entrepreneurs mostly use idea-generating method of brainstorming. Through brainstorming it is possible to generate a large quantity of possible solutions to problems. But this may also create the uncertainty of choice; that is, which alternative to choose. At this point it is perfectly appropriate to let ideas incubate, to allow time for the ideas to hatch or ferment. The difficulty here is to hurry slowly; that is, one should not wait too long, either. While timing is always critical it is a fact that even entrepreneurs need time to think. The soonest the target segment of the market has been selected entrepreneurs will then discover the extent to which they need to differentiate the product to serve the segment and look in to the costs that will be incurred to serve that segment.

Focus in entrepreneurship is beneficial for the following reasons; first, it is expensive to target whole market or many markets than to target a segment of the market. Second, entrepreneurs can discover specific expertise and market knowledge that is dependent on the specific characteristics of the market niche. An entrepreneur is able to use the knowledge to focus on serving the needs of customers in the selected market niche. Entrepreneurial focusing also makes penetration in to a new market less expensive and less complicated for the entrepreneur. Focusing approach also aims at competitive edge through differentiation or cost leadership in the product offer that the entrepreneur has settled to serve the selected segment with, because there is a clearly distinguished market niche of clients. When entrepreneurs adopt a focus method, they typically serve the specific segment market more effectively.

Focusing approach enables the entrepreneurs to offer customized and personalized products and services offerings to the target clientele. There are possibilities of competitive rivalry in the selected niches of markets that qualify normalcy in such narrowly defined market niches. In such situations, entrepreneurs can innovatively serve specialized products in a wide array of market niches. Consequently, the focus approach leads to maximization of returns from the resources deployed throughout the value addition chain. Entrepreneurs focus on the marketing push towards specified customers, offering additional services to the basic product offering to the niche, for instance, an entrepreneur may utilize electronic and computerized system which deals with matching product consumers with specialist niche that offers the specific product requirements. The basis of performance for such an entrepreneur is to adopt a focus approach by using professional knowledge and expertise in order to give the clientele an added advantage in consumption of improved and quality service or product, greater response rate to customer requests with better customer attention that is dependent on a more custom-made relationships between the entrepreneur and the client. An entrepreneur who attains a superior familiarity of the needs of the target niche, has the ability to respond promptly with appropriate flexibly to the forces shaping the operational market environment and they better provide for the customer interests, needs and wants, hence achieving customer loyalty from the clientele.

To be stable, the entrepreneur needs to do the following as part of their focus towards the market needs;

- Customer acquisition - this is where the entrepreneur creates connections with the new clientele in the market segment using techniques like; the offering various product discounts, advertising and promotion of the products on sale; or other incentives to attract new and potential customers by also offering of valueadded services to the clientele.

- Customer retention -the entrepreneur uses personalized and customized techniques retain the existing customers. These may include using information on customer database to offer a personalized and individualized service; discounts to the loyal clients; or giving customers access to specialized promotional materials from the venture. 
- Customer extension -entrepreneurs encourage customers to become more occupied with the activities of the entrepreneurial venture. This may comprise of things like sending feedback about the portfolio of the products of the venture or the venture itself.

The objectives of this study were;

i. To find out how personality trait of entrepreneurial focus influence the success of a business venture

ii. To investigate out the extent to which entrepreneurs are conscious about focus trait of personality.

\section{Literature Review}

Success refers to the achievement of goals and objectives in the business ventures that entrepreneurs engage in. For entrepreneurs; the concept of success generally refers to a firm's financial performance and growth. It has been interpreted in many different ways (Foley and Green, 1989). Perren, (2000) and Amit et al (2000) defined success from objective points of view such as profitability, revenue or a firm's growth, turnover, personal wealth creation, etc. Taormina \& Lao, (2007) and Watson et al (1998) associated entrepreneurial success with continuous operations of the venture, a venture running its business for a minimum period of three years. Other researches interpreted such success from the standpoint of intangible aspect where intangible properties for instance, goodwill of the venture is linked to the fundamental success factors of a business. In spite of the fact that business success has been an extensively studied subject in the area of entrepreneurship, no agreement has been reached as to what is to be used to evaluate the success of a business venture that can be established in literature (Perez and Caninno, 2009). This study, therefore, attempts to find out how focus as a tool as a personal factor can be the basis of success for entrepreneurial venture.

Robinson \& Sexton, (1994) opines that have instrumental personality traits that have been seen to influence the success and performance of entrepreneurial ventures. Research has also found out that some traits like tolerance of ambiguity and locus of control affected the success of business systems indirectly. (Entrialgo, Fernandez, \& Vazquez, 2000). Kiggundu (2002) found out that when demographic variables are brought into perspective, personality traits directly influence the success of African businesspersons. Inspite of the fact that studies about personality traits held a substantial role in revealing the causes of the success of entrepreneurs around the globe, they have been slated on empirical and theoretical foundations on this field of entrepreneurship. In the research study "Who is the entrepreneur?" Gartner (1988) declared, "Who" is the incorrect question. Instead entrepreneur's personality is relative to the performance of a venture from the startup to more specific facilitative processes. This study is aimed at bringing the influence of focus trait for an entrepreneur, which has not been researched by previous researchers.

Frese and Fay (2001) conducted a study on a group of organizational personnel which revealed that those having greater personal inventiveness worked better in the workplace. The research about personal inventiveness concentrated on the personal initiative of entrepreneurs: how to find and capitalize on opportunity with their hands-on approach, how they pursue success with their hands-on attitude, and how to find answers to overcome barriers and reach their intended objective (Frese, Fay, Hilburger, Leng, \& Tag, 1997; Frese, Kring, Soose, \& Zempel, 1996). Entrepreneurs with greater initiative were able to beat their challengers, and are examples to be imitated by the other employees within the organization. Initiative is objective and actionoriented (Frese et al., 1997) and, therefore, closely related to an active plans of actions. It is a psychological variable that justifies the reason whether an individual has what it takes to run an entrepreneurial entity. Entrepreneurs who have high personal initiative are people who initiate actions and are proactive from the standpoint of determining the success of venture start-ups or to productively lead a venture to growth-stage. Personal initiative, represents the individual's potential to self-start, be proactive, and overcome the barriers that stand in the way of realization of the desired objective. Most of the studies carried on personal initiative are in relation to workforce performance and probably few studies have been done on personal initiative relative to entrepreneurial success.

Human capital was considered a passive approach (where individuals simply reacted to their environment according to what one possessed), was quite extensively studied unlike personal initiative. The theory that related with human capacity and knowledge is known as Human capital, and it includes the education level, management experience and the experience in the industry. Literature review exposed that human capital helps to start-up and grow business ventures. However it was also established that human capital had positive and negative results relative to the success and failure of entrepreneurs in their ventures. Human capital variables of the entrepreneurs such as education, family-environment, work history, age, role models and support networks had been noted to contribute to entrepreneurial venture success (Hisrich, 1990; Krueger, 1993).

The basic was found to be that assumption is greater human capital of entrepreneurs intensifies the possibilities of ventures success and survival (Dyke, Fischer, \& Reuber, 1992; Bruederl \& Preisendoerfer, 1998). Lussiers and Pfeifer (2001) empirically established that in addition to capabilities and personality 
qualities, human capital of the individual entrepreneur have a role in building on to the success of the entrepreneurs.

Competency, being one of the most crucial determinants to ensure the performance of a new ventures, entrepreneurs encounter even bigger challenge when they successfully bring their businesses to growth and as the venture moves into growth stage, it experiences what observers may refer to as strategic reflection point (Grove, 1996). Strategic reflection point denotes a time in the life of the venture when the basic operations have profoundly changed. In the views of Adizes (1979), and Greiner (1972), organizations develop through steady, foreseeable stages of growth known as life-cycle stages. In the start-up phase, the venture deals with discovering and creating the product or service to be offered, establishing a market segment, attracting new customers, and manufacturing and promoting the product offering (Flamholtz, 1986). Once the venture starts to grow rapidly, it needs to have more defined structures and organization because of the growth in functional undertakings of the business. At the growth phase, the entrepreneur is obligated to focus on the long-term permanency while preserving the inventive and commercial spirit that made the venture successful at first. The entrepreneur plays a crucial role in the long-term business growth of a new venture as the founding member of the business. The entrepreneurial frontrunner defends the vision of the venture and inspires others, for example, the investors, the venture capitalists, the bankers, the customers and the employees to maintain the vision. As the company continues to grow, the founder ought to focus and emphasize on the various areas of competencies and aptitudes so as to lead the company to long-term venture performance.

Bruerderl and Preisendoerfer (1998) established in their study that social networking support is closely related to both, existence and development of a newly founded business venture. The basic assumption of the network approach is that entrepreneur have the ability to consolidate and direct networks between individuals and organizations and it is very critical for starting up a venture and as well as its success. (Birley, Cromie \& Myers, 1991). Support from informal links for instance; relatives, friends, previous employers and associates have profound benefit to the business. Thus another aim of this study was to examine to what extent social network support significantly contribute to the success of managing companies at growth stage.

\section{Methodology}

This study was carried out in Migori county, Rongo town, located in Nyanza province of Kenya. The participants of the study were informed of its purpose and willingly agreed to take part in the realization of the study objectives. Semi-structured interview questionnaires and observation schedules were used to collect the information that formed the basis of analysis for the study. Document analysis also provided a pivotal basis to back up the findings of the data collection tools. The researcher administered the research instruments on the respondents. Convenient sampling technique was used to select the participant entrepreneurs who participated in the study. The analysis of the findings was purely qualitative. The interviews and the observations of the entrepreneurs happened into their places of work and they were interviewed following the interview questionnaires, to determine how their personality trait of entrepreneurial focus influence the success of a business venture while the observation schedule was used to investigate the extent to which entrepreneurs are conscious about focus trait of personality. The researcher also engaged the research participants in the research in finding out how they felt about the focus trait of an entrepreneur while observing their conscious behavior while handling their business. The study was carried out for a period of one month, with 15 entrepreneurs being interviewed to give the responses to the interviews that the researcher recorded on the questionnaires and a return visit was conducted to affirm the observations for the study, with the researcher establishing rapport with the entrepreneurs to ensure that the responses given were independent and free from bias of suspicious research.

\section{Findings}

Entrepreneurs must venture in to a venture that is new, by means of creating a new idea, process, product or service. Alternatively, entrepreneurs may change an existing idea, product, process or service to appear different from what other players in the market are offering. In response to this, most of the interviewed participants said that they trade with the existing products in the market, but are interested in differentiating the delivery process. For instance, three respondents said that they differentiate their product by offering home delivery services which is perceived to be expensive by the competitors in the area. This view is in line with Schumpeter (1934) who viewed innovation to be the foundation of value creation where novel amalgamations of resources led to production of new products, production approaches, and markets or supply sources. Likewise, Innovations may involve the recombination of old ideas or a distinctive approaches that are perceived as new by the persons involved (Van de Ven et al., 1999).

The participants of the study felt that just a new product or process in the market they serve is not enough, for they require a mix of innovation in addition to their entrepreneurial capabilities. This helps them to know how to change an idea into a product that customers need. This is in line with the views of Enz (2005) who observes that in many instances the new idea requires the creation of a new business to produce and sell the 
idea to customers. The study participants felt that as an approach to focus on the venture, there are a number of ways, including products, services, marketing channels processes, and business models, with the goal of sustaining or taking business ventures to new markets. Focus helps entrepreneurs by inducing the desire to reduce costs through greater efficiencies in business operations. (Harrison and Enz, 2005).

To achieve focus in their businesses, the entrepreneurs agreed that they needed to have a culture that supports improvement and the ability to identify the opportunities and threats in the environment they thrived in. One of the interviewees said "this business of mine thrives because of my ability to engage the support of my juniors, whom we word as a team and collaborate in all aspects of the operation, because I can manage on my own. I direct them on what I want done and at times delegate some of my duties. My employees have excellent communication skills, and are learning every other day, and sometimes bring in new ways of doing things in my shop. I usually reward them to encourage them to be successful managers in future." In fact a ventures success may depend more on the summative innovation orientation that produces potential for innovation and less on exact innovations. (Harrison and Enz, 2005). To realize focus in entrepreneurship, Siguaw, Simpson and Enz (2006) brought forth a concept of an organizational innovation system or orientation developed and they defined innovation as: 'A multidimensional knowledge structure composed of a learning philosophy, strategic direction and trans-functional beliefs that guides and directs all organizational strategies and actions, including those embedded in the formal and informal systems, behaviors, competencies, and processes of the firm' which is very necessary. The concept denotes that entrepreneurs need to be all round, constantly monitoring their operational environments and responding to ensure that their businesses thrive successfully. Siguaw et al., (2006) further opines that orientation encourages innovative thinking and supports successful development, progression, and implementation of innovations. Having an orientation toward innovation means developing a pervasive set of understandings about learning, thinking and acquiring, transferring and using knowledge.

During the research period, the researcher was involved in observation of the habits and behavior of the research participants during their business operations. It was observed that entrepreneurs have the habit of paying close and constant attention to the tasks they engage in. the observation strengthens the responses they gave on how they maintain focus on their working. Most of those observed were usually busy for the better part time of their business commitments either making constant calls or doing some manual work in their ventures. Others were committed reading documents and checking transaction records to monitor the documentation of their operations. This is because they were keenly focused to see their ventures succeed and they had constant desire for correcting any deviation of the observed performance from the planned performances of their ventures. This is consistent with the views of Quinn, (1985) who feels that strategic direction is a "way of thinking and leading' that drives the venture in the long run in the innovation-orientation framework, keeping it constantly innovative, and clear in its thought and purpose, whose direction is fundamentally articulated through vision and mission statements and the venture goals.

Entrepreneurs develop a culture of working that is guided by the purpose, objectives and missions of the venture. Their way of business supports their vision by reassuring their work teams to discuss new ideas and take risks. The organization should not only tolerate failures, but also encourage employees and managers to learn from their mistakes. (Kuratko and Hodgetts, 2001). This was confirmed by the researchers by the observation. The entrepreneurs were seen to keep a close check on the progress of work in their ventures. This commitment to monitoring of operation brings another angle of looking at entrepreneurial focus from the actual work that an entrepreneur engages in within their ventures.

Focus in entrepreneurship can be looked at from the perspective of the ventures various functional areas. Knowledge is transferred by the various operational managers across and along the entrepreneurial venture to create a productive interrelationship that leads to win-win success of the segregated operational departments. Sivadas and Dwyer (2000) feel that entrepreneurs need mechanisms to link departmental "thought worlds" so that insights from each individual departments can be merged to bring out new products that capture the collective insight of everyone involved'. A culture that encourages entrepreneurial focus allows employees and managers to consider challenging the old ideas by instilling an obligation to continuous learning and strategic transformation. 'Past wisdom should not be a constraint but rather something worth challenging. Yesterday's performance formula should be viewed as today's obsolete dogma.' The research participants took concurred with the findings of the scholar and affirmed that focused entrepreneurs will always have focused departments and the overall focus is towards the overall success of the whole venture.

Entrepreneurial focus is emerges from a ventures with a culture that is inclined to value the ideas of every individual within the ventures. It goes in to making each and every individual within the venture responsible for looking into new ways of doing normal and usual activities within the organization, which is essential approach to foster solid focus cultures for conducting the business. This research unearthed the matter as a fundamental ingredient to the success of the ventures. Hamel, (2001) affirms that, 'Many companies have succeeded in making everyone responsible for quality'. The outstanding employees are focused to seek the best means to the ends and therefore, this leads to venture culture of best work practices. 


\section{Conclusion And Recommendations}

This research was meant to find out how personality trait of entrepreneurial focus influence the success of a business venture and investigate out the extent to which entrepreneurs are conscious about focus trait of personality. As part of the insight from the results, the major conclusions are that the personality trait of entrepreneurial focus influences the success of business ventures and the entrepreneurs are usually conscious of the focus trait of their personality when conducting business in their ventures. Based on these conclusions, the researcher recommends that individuals who need to set up successful business entities need to have and use the focus aspect of personality and should not pay conscious attention to the fact that they are really conscious. The researcher further recommends a future research to be conducted on other potential personality traits and factors that may contribute to the success of entrepreneurs and their potential businesses.

\section{References}

[1]. Casson, M. (1982). The Entrepreneur: An Economic Theory, 2nd edn. Cheltenham, UK and Northampton, MA, USA: Edward Elgar.

[2]. Foley, P. \&. (1989). Small Business Success. London, England: Paul Chapman Publishing.

[3]. Perren, L. (2000). Factors in the growth of micro-enterprises: Exploring the implications. Journal of Small Business and Enterprise Development, $58-68$.

[4]. Taormina, J. \&. (2007). Measuring Chinese entrepreneurial motivation: Personality and environmental influences,. International Journal of Entrepreneurial Behavior and Research, 200-221.

[5]. Watson, K. H.-S. (1998). Small business start-ups: Success factors and support implication. Journal of Entrepreneurial Behavior and Research, 217-238.

[6]. Perez, E. \&. (2009). The importance of Entrepreneur's perception of success. Review Of International Comparative Management, 990-1010.

[7]. Robinson, P. B. (1994). The effect of education and experience on self-employment success. Journal of Business Venturing, 9(2), 141-156.

[8]. Entrialgo, M. F. (2000). Psychological characteristics and process: the role of entrepreneurship in Spanish SMEs. European Journal of Innovation Management, 137-151.

[9]. Kiggundu, M. N. (2002). Entrepreneurs and entrepreneurship in Africa: What is known and what needs to be done. Journal of Developmental Entrepreneurship, 239-258.

[10]. Gartner, W. B. (1988). Who is an entrepreneur? Is the wrong question. American Journal of Small Business, 11-32.

[11]. Frese, M. \&. (2001). Personal initiative (PI): An active performance concept for work in the 21st century. Amsterdam: Elsevier Science.

[12]. Frese, M. K. (1996). Personal Initiative at work: Differences between East and West Germany. The Academy of Management Journal, 39(1), 37-63.

[13]. Frese, M., Fay, D., Hilburger, T., Leng, K., \& Tag, A. (1997). The concept of personal initiative: Operationalization, reliability and validity in two German samples. Journal of Organizational and Occupational Psychology, 70, 139-161.

[14]. Hisrich, R. D. (1990). Entrepreneurship/Intrapreneurship. American Psychologist, 45 (2), 209-222.

[15]. Krueger, N. (1993). The impact of prior entrepreneurial exposure on perceptions of new venture feasibility and desirability. Entrepreneurship: Theory and Practice, 18 (1), 5-21.

[16]. Dyke, L. S., Fischer, E. M., \& Reuber, A. R. (1992). An inter-industry examination of the impact of owner experience on firm performance. Journal of Small Business Management, 30 (40), 72-86.

[17]. Lussiers, R. N., \& Pfeifer, S. (2001). A crossnational prediction model for business success. Journal of Small Business Management, 30(3), 228-239.

[18]. Adizes, I. (1979). Organizational passages: Diagnosing and treating life cycle problems in organizations. Organizational Dynamics, 9 (Summer), 3-24.

[19]. Greiner, E. (1972). Evolution and revolution as organizations grow. Harvard Business Review, 50 (4), 37-46

[20]. Flamholtz, E. G. (1986). How to Make the Transition from an Entrepreneurship to a Professionally Managed Firm. London: Jossey-Bass Publishers.

[21]. Bruederl, J., \& Preisendorfer, P. (1998). Network Support and the Success of Newly Founded Businesses. . Small Business Economics, 10 (3), 213-225.

[22]. Birley, S., Cromie, S., \& Myers, A. (1991). Entrepreneurial networks: their emergence in Ireland and overseas. International Small Business Journal, 9, 56-73.

[23]. Schumpeter, J. (1934). The Theory of Economic Development. Cambridge MA: Harvard University Press.

[24]. Ven, V. d. (1999). Developmental processes of cooperative inter-organizational relationships. Academy of Management Review, 19, pp. $90-118$.

[25]. Enz, C., \& Harrison, J. (2005). Innovation and entrepreneurship in the hospitality industry[Electronic version]. New York: Cornell University, School of Hotel Administration.

[26]. Siguaw, J. A., Penny M. Simpson, \& Cathy A. Enz. (2006). Conceptualizing Innovation Orientation: A framework for study and integration of innovation research. Journal of Product Innovation Management, Vol 23.

[27]. Quinn, J. B. (1985). Managing innovation: Controlled chaos. Harvard Business Review, May-June, 73-84.

[28]. Kuratko, D. F., \& Hodgetts, R. M. (2001). Entrepreneurship: A Contemporary Approach. Mason, OH: South-Western Thomson Learning.

[29]. Sivadas, E., \& Dwyer, R. F. (2000). An examination of organizational factors influencing new product development in internal and alliance-based processes. Journal of Marketing, 64, pp. 31 - 40.

[30]. Hamel, G. (2001). Vallankumouksen kärjessä (Leading the revolution). Helsinki: WSOY. 